Article

\title{
Thin Film Nanocomposite Membrane Filled with Metal-Organic Frameworks UiO-66 and MIL-125 Nanoparticles for Water Desalination
}

\author{
Mohammed Kadhom ${ }^{1,2}$, Weiming $\mathrm{Hu}^{3}$ and Baolin Deng ${ }^{1,3, *}$ \\ 1 Department of Chemical Engineering, University of Missouri, Columbia, MO 65211, USA; \\ makbq6@mail.missouri.edu \\ 2 Al-Dour Technical Institute, Northern Technical University, Al-Dour, Saladin, Iraq \\ 3 Department of Civil and Environmental Engineering, University of Missouri, Columbia, MO 65211, USA; \\ why78@mail.missouri.edu \\ * Correspondence: dengb@missouri.edu; Tel.: +1-573-882-0075
}

Academic Editor: Mohamed Khayet

Received: 10 May 2017; Accepted: 9 June 2017; Published: 14 June 2017

\begin{abstract}
Knowing that the world is facing a shortage of fresh water, desalination, in its different forms including reverse osmosis, represents a practical approach to produce potable water from a saline source. In this report, two kinds of Metal-Organic Frameworks (MOFs) nanoparticles (NPs), UiO-66 ( 100 nm) and MIL-125 ( 100 nm), were embedded separately into thin-film composite membranes in different weight ratios, $0 \%, 0.05 \%, 0.1 \%, 0.15 \%, 0.2 \%$, and $0.3 \%$. The membranes were synthesized by the interfacial polymerization (IP) of $m$-phenylenediamine (MPD) in aqueous solution and trimesoyl chloride (TMC) in an organic phase. The as-prepared membranes were characterized by scanning electron microscopy (SEM), transmission electron microscopy (TEM), contact angle measurement, attenuated total reflection Fourier transform infrared (ATR FT-IR) spectroscopy, and salt rejection and water flux assessments. Results showed that both UiO-66 and MIL-125 could improve the membranes' performance and the impacts depended on the NPs loading. At the optimum NPs loadings, $0.15 \%$ for UiO- 66 and $0.3 \%$ for MIL-125, the water flux increased from $62.5 \mathrm{~L} / \mathrm{m}^{2} \mathrm{~h}$ to 74.9 and $85.0 \mathrm{~L} / \mathrm{m}^{2} \mathrm{~h}$, respectively. $\mathrm{NaCl}$ rejection was not significantly affected (UiO-66) or slightly improved (MIL-125) by embedding these NPs, always at $>98.5 \%$ as tested at 2000 ppm salt concentration and 300 psi transmembrane pressure. The results from this study demonstrate that it is promising to apply MOFs NPs to enhance the TFC membrane performance for desalination.
\end{abstract}

Keywords: metal-organic framework; thin film nanocomposite membrane; reverse osmosis; desalination; nanoparticles

\section{Introduction}

Reverse osmosis (RO) is now the most employed method of desalination to convert saline or brackish water source to freshwater. The process uses a membrane as a selective barrier through which water molecules, but not the salts or organics, pass under pressure [1]. Desalination by various approaches, especially $\mathrm{RO}$, represents a solution to address the water shortage problem that has become increasingly serious in the recent decades [2]. Development of $\mathrm{RO}$ processes and membranes has gone through many stages and forms since the first applicable membrane synthesis in the early 1960s [3]. The state-of-the-art membrane is the thin film composite (TFC) membrane invented by John Cadotte in the early 1980s. The TFC membrane has a polyamide dense layer with a thickness of a few hundred nanometers supported by an ultrafiltration membrane. This polyamide layer is the active 
layer for salt rejection, formed by the interfacial polymerization of the MPD dissolved in water and TMC dissolved in organic solvent [4].

Numerous researches have been devoted to developing and improving the performance of TFC membranes [5]. One approach is to embed nano-sized materials such as zeolite [6-12], silica [13-18], titanium dioxide [19-22], or carbon nanotubes [23-25] inside the membrane to improve its properties and performance. Another way is to select proper materials and control the manufacturing conditions affecting the membrane's efficiency [6,26-29]. In addition, the engineering process could be optimized to increase the pure water production efficiency and lower the energy cost [30-34].

Metal-Organic Frameworks (MOFs) are a class of materials consisting of an inorganic or metal core surrounded by an organic linker material [35]. MOFs have very high specific surface area, a high number of adsorption sites, different particle structures, distinct pore size and structure, and can be applied for various purposes [35-39]. These include applications for ion exchange [40], light harvesting [41], sensing [42], catalyst [43], drug delivery [44], gas storage [45,46], and separation $[47,48]$. Such a wide range of applications are possible because MOFs can be easily designed toward desired uses.

MOFs have been widely used for gas separation. Their porous structure can generate exceptionally high pore volume and surface area reaching over $7000 \mathrm{~m}^{2} / \mathrm{g}$ [49], which is particularly suitable for gas storage and separation. Beginning with the first MOFs membrane synthesized and used for gas separation [50], different forms of MOFs membranes have been prepared, often on an organic or inorganic support layer. MOFs particles have been incorporated into polyamide layer of thin film nanocomposite (TFN) membrane with improved properties [35,51]. In water treatment, MOFs have been used as adsorbents of heavy metals and as fillers in alumina hollow fiber membranes for water desalination [52,53]. MOFs have also been employed in TFN membrane to treat water in different applications. Lee et al. used A100 (aluminum terephthalate) and C300 (copper benzene-1,3,5-tricarboxylate) as water soluble MOFs, which were embedded and dissolved into the ultrafiltration membrane to increase its porosity [54]. For reverse osmosis, Hu et al. [55] and Gupta et al. [56] reported two simulation studies that used Zeolitic Imidazolate Framework (ZIFs)-MOFs based on zeolite as membranes for water desalination. Xu et al. [57] filled MIL-101(Cr) NPs into the TFN membrane to improve the desalination performance. Findings showed that the water flux increased by $44 \%$ comparing to the plain membrane by adding $0.05 \%$ MIL-101 NPs to the organic solution, while the salt rejection remained almost the same. Similar outcomes were observed by Ma et al. [58] when embedding UiO-66 in membranes used in forward osmosis. By loading 0.1\% NPs to the membrane, the water flux increased from 2.19 to $3.33 \mathrm{LMH} /$ bar. Nevertheless, the use of MOFs membranes in water treatment is still in its infancy when compared with their applications for gas separation.

UiO-66 (MOFs based on zirconium) [59] and MIL-125 (MOFs based on titanium) [60] are water stable, carboxylate ligand-based MOFs [61]. The materials possess many metal atom centers, which give them high structural symmetry and steadiness. Figure 1 shows these structures as reported by Wang et al. [52] for UiO-66 and Devic and Serre for MIL-125 [62]. Properties including their high surface area, chemicals resistance, and functionalization ability made these MOFs good candidates for different applications $[63,64]$.

In this paper, UiO-66 and MIL-125 MOFs nanoparticles were synthesized and then embedded into the TFN membrane. The NPs were incorporated by mixing different amounts of materials $(0-0.3 \mathrm{wt} \%)$ in the trimesoyl chloride solution during membrane fabrication, and the membranes' performance in reverse osmosis application was tested. MOFs NPs were characterized by SEM, zeta potential measurement, and surface area evaluation, while the membranes' physicochemical properties were examined by SEM, TEM, contact angle, and ATR FT-IR tests. It was found that embedding UiO-66 and MIL-125 NPs to the TFN membrane improved its performance to a level that is considered to be among the best for brackish water desalination. 

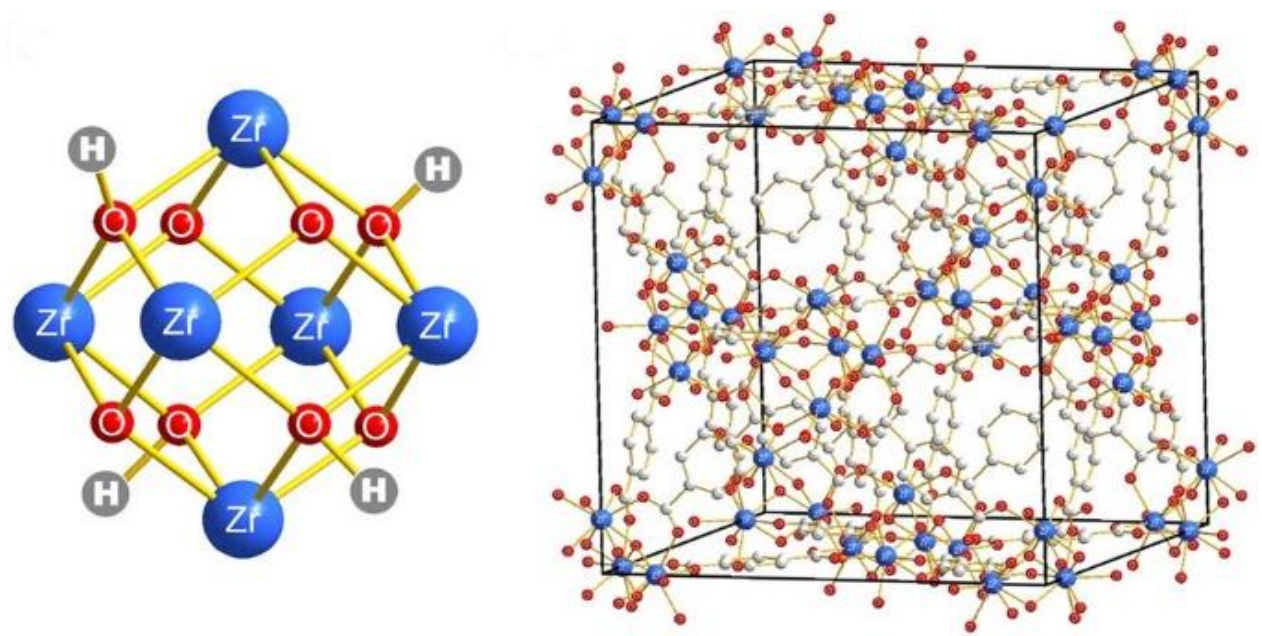

(a)
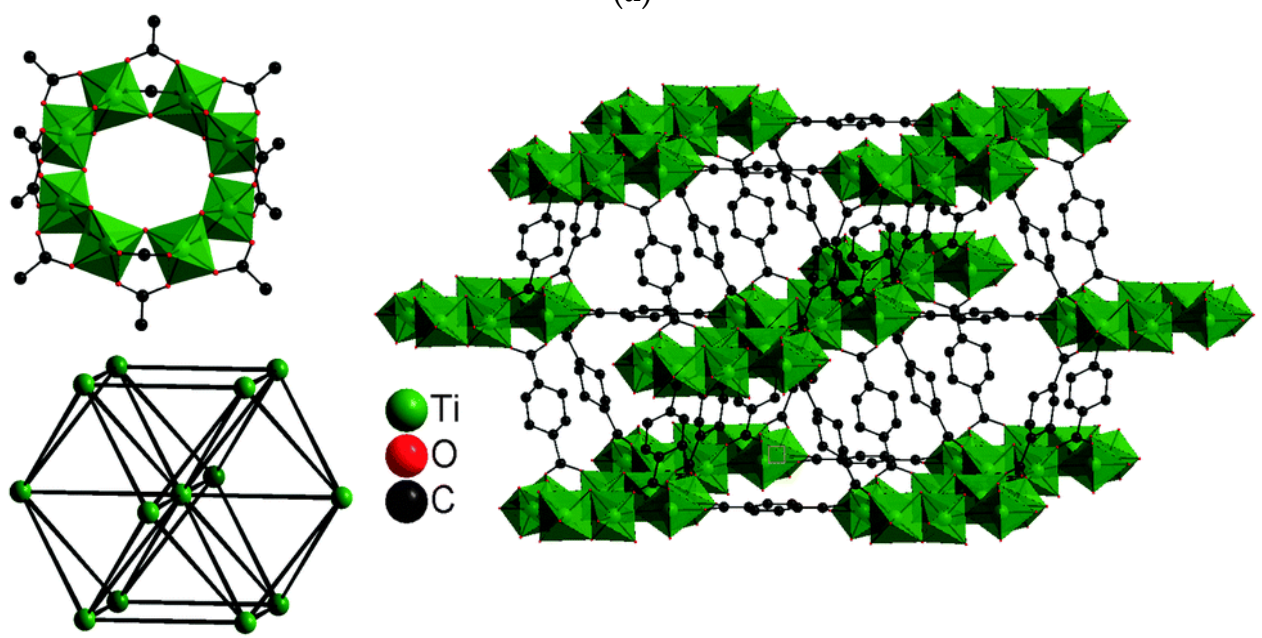

(b)

Figure 1. Metal-Organic Frameworks (MOFs) structure: (a) UiO66 [52], reproduced with permission from Springer Nature and (b) MIL-125 [62], reproduced with permission from Royal Society of Chemistry.

\section{Materials and Methods}

\subsection{Materials}

Zirconium (IV) chloride $\left(\mathrm{ZrCl}_{4}, 99.5 \%\right)$, titanium (IV) isopropoxide ( $\left.\mathrm{Ti}\left[\mathrm{OCH}\left(\mathrm{CH}_{3}\right)_{2}\right]_{4}, 97 \%\right)$, 1,4-benzenedicarboxylic acid (BDC, 98\%), dimethylformamide (DMF, 99.9\%), and methanol $\left(\mathrm{CH}_{3} \mathrm{OH}, 99.8 \%\right)$ were obtained from Sigma-Aldrich (St. Louis, MO, USA) for the preparation of MOFs NPs.

The PSU support sheets were prepared by dissolving polysulfone pellets (PSU, $M_{\mathrm{W}}=35,000$, Sigma-Aldrich) in DMF solvent. The chemicals for the IP, $m$-phenylenediamine (MPD, $\geq 99 \%$ ) and trimesoyl chloride (TMC, $\geq 98.5 \%$ ), were purchased from Fisher Scientific (Pittsburgh, PA, USA) and Sigma Aldrich, respectively. 2,2,4-trimethylpentane (isooctane, 99\%) was obtained from Fisher Scientific and used as TMC solvent. Our recent study demonstrated that isooctane could replace commonly used hexane during the IP process as a more environmental-friendly solvent [18]. Millipore DI water (Synergy185, 18.2 M $\Omega$-cm, EMD Millipore Corp., Billerica, MA, USA) was used to prepare MPD solution and for cleaning purposes. Calcium chloride $\left(\mathrm{CaCl}_{2}\right)$ and sodium chloride $(\mathrm{NaCl})$ were obtained from Fisher Scientific and Sigma Aldrich, respectively. CSA/TEA salt materials, 
triethylamine (TEA, $\geq 99 \%$ ) and (1s)-(+)-10-camphorsulfonic acid (CSA, 99\%), were purchased from Sigma Aldrich.

\subsection{Synthesis and Characterizations of MOFs NPs}

UiO-66 and MIL-125 MOFs NPs used in this research were synthesized through the microwave and solvothermal methods, respectively. For UiO-66 preparation, $\mathrm{ZrCl}_{4}, \mathrm{BDC}$, and $\mathrm{H}_{2} \mathrm{O}$ were dissolved in DMF under stirring in molar ratios of 1:1:1:500, respectively [52]. After a complete mixing, the solution was placed in a GE microwave (Model no. J VM131K 002) and irradiated for 5 min at a power of $220 \mathrm{~W}$. The $5 \mathrm{~min}$ irradiation was separated into 4 steps: $2 \mathrm{~min}, 1 \mathrm{~min}, 1 \mathrm{~min}$, and $1 \mathrm{~min}$ with 1 min relaxing time between each irradiation section to prevent solvent from heating over boiling point. The MOF precipitates appeared during the last 2 steps of irradiation. MIL-125 NPs were prepared in different formula, in which $3 \mathrm{mmol} \mathrm{Ti}\left[\mathrm{OCH}\left(\mathrm{CH}_{3}\right)_{2}\right]_{4}, 6 \mathrm{mmol} \mathrm{BDC}, 50 \mathrm{~mL}$ methanol, and $20 \mathrm{~mL}$ acetic acid were dissolved in $100 \mathrm{~mL}$ DMF [60]. After mixing, the solution was transferred to a $500 \mathrm{~mL}$ Teflon liner and put into a metallic digestion bomb at $150{ }^{\circ} \mathrm{C}$ for $24 \mathrm{~h}$. Precipitates of both MOFs were washed and centrifuged with DMF and methanol, three times each. The washed samples were dried in an oven overnight at $80^{\circ} \mathrm{C}$ and collected for later use.

The NPs size and morphology were tested by SEM (Hitachi S-4700 Field Emission Scanning Electron Microscope, Hitachi, Ltd., Tokyo, Japan). First, the particles were spread on a carbon adhesive disc. After that, they were coated with platinum on a sputter coater (K575x, Emitech, Kent, UK) for $1 \mathrm{~min}$ at 20 milliAmps, prior to imaging. Zetasizer (Malvern nano series, Malvern Instruments Ltd., Malvern, UK) was used to measure the NPs zeta potential. $0.1 \mathrm{~g}$ of the NPs was placed in $20 \mathrm{~mL}$ DI water of $\mathrm{pH} 5.7$ and sonicated for $10 \mathrm{~min}$ to avoid aggregation. The specific surface area was determined by $\mathrm{N}_{2}$-adsorption using the Beckman coulter SA 3100 (Beckman Coulter, Inc., Brea, CA, USA) surface area analyzer, according to the Brunauer-Emmett-Teller (BET) method.

\subsection{Preparation of PSU Support Sheets}

The casting solution was made by dissolving $15 \mathrm{wt} \%$ of PSU grains in DMF. The solution was heated to $60^{\circ} \mathrm{C}$ and stirred for at least $5 \mathrm{~h}$, till a colorless solution formed. The solution was removed from the heater and cooled down at room temperature while allowing vent of the organic vapor; then left overnight for degassing.

A solution aliquot was spread over a glass plate and cast to a thickness of $130 \mu \mathrm{m}$ by a casting knife (EQ-Se-KTQ-150, MTI Corp., Richmond, CA, USA). The glass plate with the PSU solution was directly immersed into a water bath. The colorless solution then turned to a white sheet instantly and detached from the glass in a few seconds, in a process of phase inversion. The support sheets were collected and washed three times in DI water for the removal of any remaining solvent. Finally, the sheets were stored in DI water at $4{ }^{\circ} \mathrm{C}$ for at least $24 \mathrm{~h}$ before use.

\subsection{Preparation of TFN Membranes}

The prepared support sheet was placed on a piece of glass with the excess water removed by a squeegee roller. MPD solution was then poured on the PSU sheet for $25 \mathrm{~s}$, then excess solution was removed by the squeegee roller. MPD solution was prepared by dissolving $2 \mathrm{wt} \%$ of MPD in DI water. The solution also contained $1 \%$ of CAS/TEA salt and $0.01 \% \mathrm{CaCl}_{2}$, which were added to improve membrane's hydrophilicity and performance. The membrane with MPD was left for 2 min to dry, then the TMC solution, which was prepared by dissolving $0.15 \mathrm{wt} \% \mathrm{TMC}$ in isooctane, was added to the sheet for $15 \mathrm{~s}$, and the reaction of TMC and MPD led to the formation of a thin polyamide film by the interfacial polymerization (IP). After disposing the extra TMC solution, the sheets were dried in oven at $80^{\circ} \mathrm{C}$ for $6 \mathrm{~min}$ for the evaporation of any residual solvent. Finally, the sheets were washed in DI water three times and stored in water at $4{ }^{\circ} \mathrm{C}$ for at least $18 \mathrm{~h}$ before test. Since the MOFs have higher dispersion affinity in organic solutions than in water due to the relatively hydrophobic organic 
shells, the MOFs NPs were dispersed in TMC solution in different loading ratios, $0.05,0.1,0.15,0.2$, and $0.3 \mathrm{wt} \%$.

\subsection{TFN Membrane Characterizations}

The prepared membranes were dried at room temperature for around $24 \mathrm{~h}$ and stored at $4{ }^{\circ} \mathrm{C}$ prior to characterizations. The membrane's morphology was examined by SEM (Hitachi S-4700). The samples were coated with platinum by a sputter coater (Emitech, K575x) for $1 \mathrm{~min}$ at 20 milliAmps. After placing the samples inside the SEM device, different voltages were used to achieve various resolutions.

The membrane's cross sectional view was observed using TEM (JEOL JEM-1400, JEOL Ltd., Peabody, MA, USA) device. The samples were prepared by soaking them in a resin (Eponate 12, Ted Pella, Inc., Redding, CA, USA) overnight, then cut by the Reichert-Jung Ultracut E ultramicrotome (Reichert, Depew, NY, USA).

The membrane surface functional groups were assessed by the ATR FT-IR spectroscopy, using the Nicolet 4700 FT-IR with the multi-reflection Smart Performer ${ }^{\circledR}$ ATR accessory (Thermo Electron, Waltham, MA, USA).

The contact angle between DI water drop and membrane's surface was measured to understand the surface hydrophilicity. A sessile drop technique-based contact angle video system, VCA-2500 XE (AST products, Inc., Billerica, MA, USA), was employed for this measurement. Each reported value of contact angle was the average of six measurements tested on different locations.

A cross flow reverse osmosis system was used to measure the water flux and salt rejection as shown in our previous work [18]. The membrane was placed in a filter holder cell (HP Filter Holder, $47 \mathrm{~mm}$, stainless steel, EMD Millipore, Billerica, MA, USA) and tested, under conditions of 300 psi, $25{ }^{\circ} \mathrm{C}$, and $2000 \mathrm{ppm} \mathrm{NaCl}$ solution, for eight hours. The permeate water flux was calculated based on its transferred volume per unit time; the LABVIEW software was used to track the water flux, calculated based on Equation (1).

$$
J=\frac{V}{A \times t}
$$

where $J$ is the water flux $\left(\mathrm{L} / \mathrm{m}^{2} \mathrm{~h}\right), V$ the permeate water volume $(\mathrm{L}), A$ the membrane area $\left(\mathrm{m}^{2}\right)$, and $t$ the accumulation time (h).

A conductivity meter (HACH Company, Loveland, CO, USA) was employed to measure the total dissolved salts in feed solution and permeate water. $\mathrm{NaCl}$ rejection was calculated by Equation (2).

$$
R=\left(1-\frac{C_{p}}{C_{f}}\right) \times 100
$$

where $R$ is the salt rejection ratio, $C_{p}$ the permeate conductivity and $C_{f}$ the feed conductivity.

The salt solubility maintained the same by controlling the system temperature at $25^{\circ} \mathrm{C}$ using external water bath.

\section{Results and Discussion}

\subsection{MOFs NPs Characterizations}

UiO-66 and MIL-125 NPs had measured surface areas of 293.6 and $515.5 \mathrm{~m}^{2} / \mathrm{g}$, respectively. Although these numbers seem to indicate the materials are highly porous, they are low compared with what had been reported in the literature $[60,65]$. The reason for this difference is not clear but the materials' aggregation could have contributed to the difference.

The zeta potential values of UiO- 66 and MIL-125 NPs were $7.66 \mathrm{mV}$ and $-46.1 \mathrm{mV}$, respectively, when they were tested at a concentration of $0.1 \%$ in DI water. Although both zirconium and titanium could be in the oxidation state of +4 , different surface charges, positive and negative, were measured 
for UiO-66 and MIL-125, respectively. The measured zeta potential of UiO-66 at pH 5.7 was close to the literature-reported value of $0 \mathrm{mV}$ at almost the same $\mathrm{pH} 5.5$ [66]. MIL-125's zeta potential was lower than what was previously reported, around $+2 \mathrm{mV}$ at $\mathrm{pH}$ of $5.5[67,68]$. This could be due to the use of different titanium raw materials; titanium isopropoxide was used in this research instead of titanium butoxide used in previous studies.

Figure 2a,b presents the SEM morphology of UiO-66 (100-200 nm, cubic shape) and MIL-125 (100 nm, spherical shape) respectively. The sizes of NPs were appropriate to be embedded in TFN membranes, as it would be shown later.

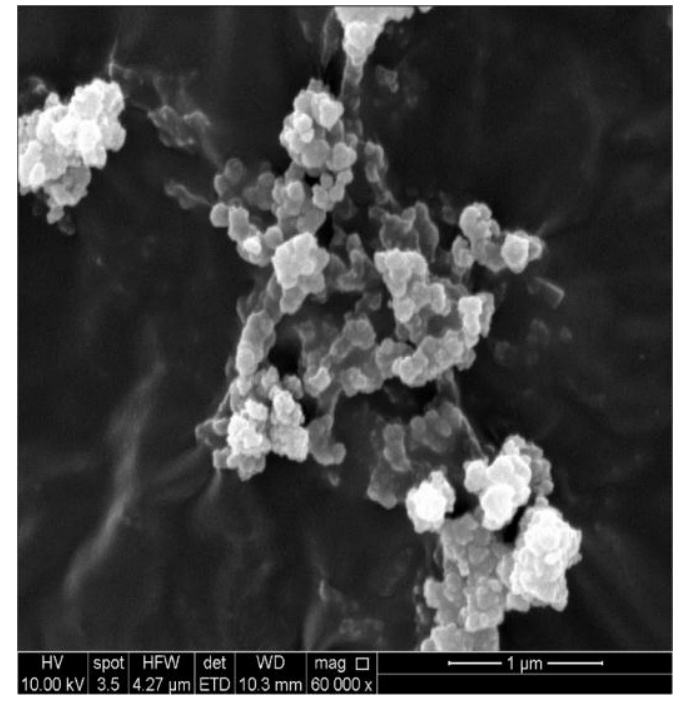

(a)

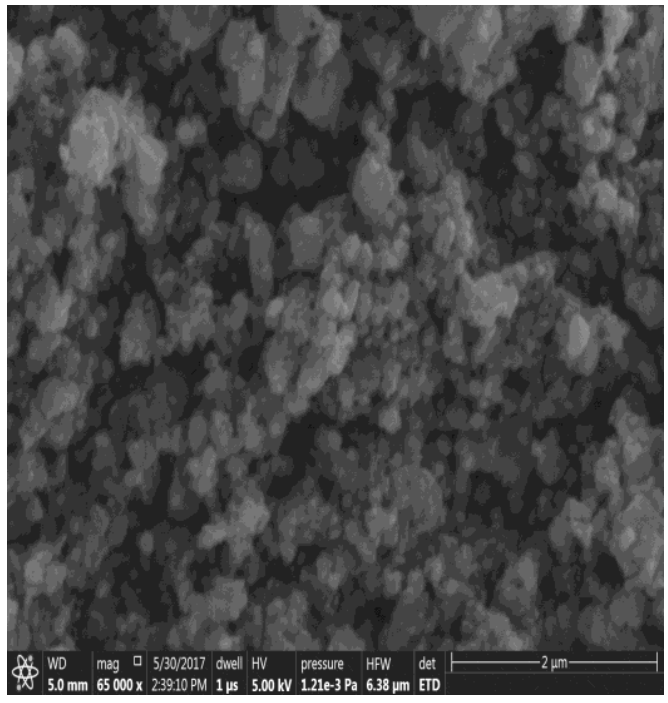

(b)

Figure 2. Scanning electron microscopy (SEM) images for (a) UiO-66 and (b) MIL-125 MOFs nanoparticles (NPs).

\subsection{TFN Membrane Characterizations}

ATR FT-IR spectra were collected from the surface of various membrane specimens. The spectra of the PSU support sheet, TFC membrane, and the TFN membranes with UiO-66 and MIL-125 NPs, respectively, were illustrated in Figure $3 a, b$. The spectral features of the PSU layer and TFC membrane chemical groups are repeated in TFN membranes spectra, in which the peaks corresponding to MOFs were also observed. Generally, by increasing NPs percentage, the reflected spectra had new peaks relevant to the embedded materials. Starting with the PSU spectrum, two featured peaks at 1150 and $1245 \mathrm{~cm}^{-1}$ were observed, which could be allocated to the $\mathrm{O}=\mathrm{S}=\mathrm{O}$ symmetric stretching of sulfone group [69] and $\mathrm{C}-\mathrm{O}-\mathrm{C}$ asymmetric stretching of aryl ethyl group, respectively [70]. The peaks at 1298 and $1325 \mathrm{~cm}^{-1}$ could indicate the asymmetric stretching of $\mathrm{O}=\mathrm{S}=\mathrm{O}$ sulfone group. At 1488 and $1590 \mathrm{~cm}^{-1}$, the peaks could be attributed to the aromatic $C-C$ stretching $[69,70]$. By adding polyamide thin film layer, peaks at 1350 and $1610 \mathrm{~cm}^{-1}$ appeared due to the $\mathrm{N}-\mathrm{H}$ deforming (amide III) and C=O (carboxylic), respectively [71]. Furthermore, N-H bending and $\mathrm{C}-\mathrm{N}$ stretching could be represented by the peak around $1545 \mathrm{~cm}^{-1}$ (amide II). The vibration at $1660 \mathrm{~cm}^{-1}$ could be assigned to the $\mathrm{C}=\mathrm{O}$ stretching (amide I) [71,72].

When MOFs NPs were added at very low amounts, new peaks corresponding to these NPs were not apparent. By increasing UiO-66 molar ratio to 0.15 and above, an obvious peak around $1380 \mathrm{~cm}^{-1}$ and a tiny one at $1565 \mathrm{~cm}^{-1}$ appeared, which could be assigned to the Zr-OH vibration [73-76], as shown in Figure 3a. At $0.3 \%$, the peak disappeared; this might be caused by the particles' aggregation so no proper NP dispersion was obtained. For MIL-125 at 0.3\%, a clear peak was observed around $1416 \mathrm{~cm}^{-1}$, which could be assigned to the Ti-O-Ti stretching vibrations [77]. 
The SEM images of membranes surface with UiO-66 and MIL-125 NPs are illustrated in Figures 4 and 5, respectively. The TFC membrane, for which there was no particles added, showed a leaf-like shape characteristic of normal polyamide layer. Addition of up to $0.05 \%$ UiO-66 NPs did not cause much change in leaf-like morphology, as illustrated in Figure $4 \mathrm{~b}$. When the loading was increased to $0.1 \%$ and $0.15 \%$, the membranes' surface began to change due to NPs filling into the membrane. The nanoparticles covered a wide area and had a good distribution in the membrane structure. At $0.2 \%$ and $0.3 \%$, the solid clusters / aggregates were easily observable, which might have an impact on salt rejection. At loading of $0.3 \%$, the NPs aggregated and formed even larger clusters, and covered the surface more sparsely. This is consistent with the FT-IR results and trends, as discussed in the previous section.

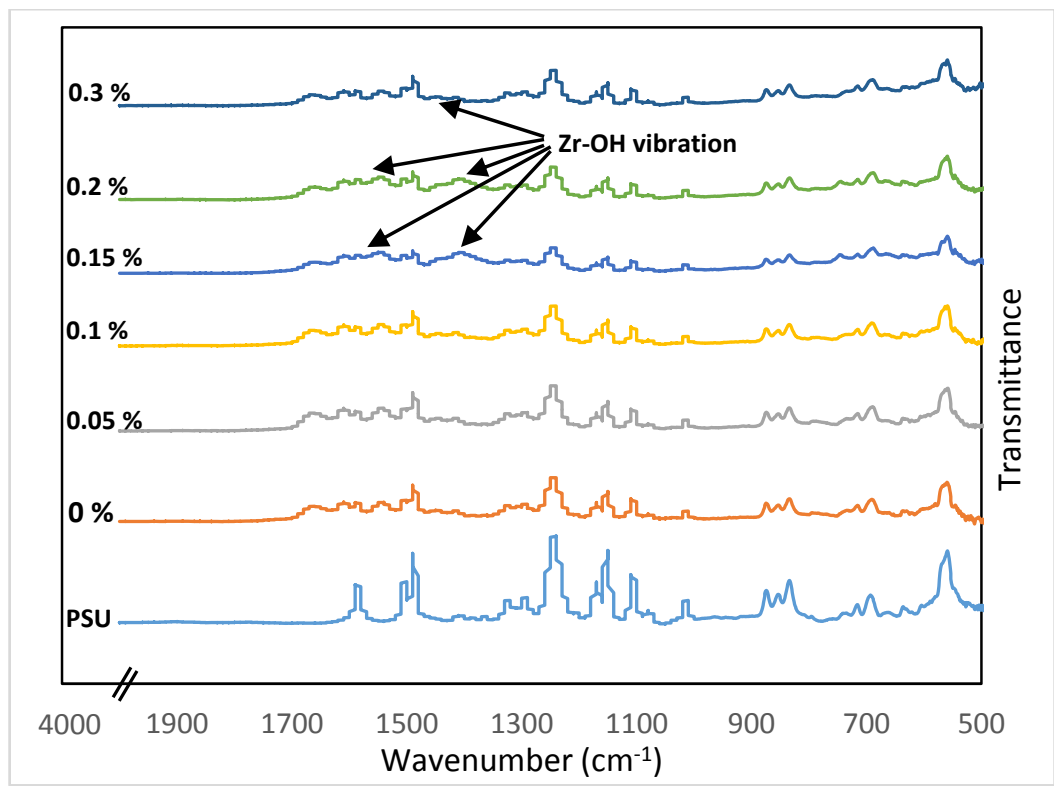

(a)

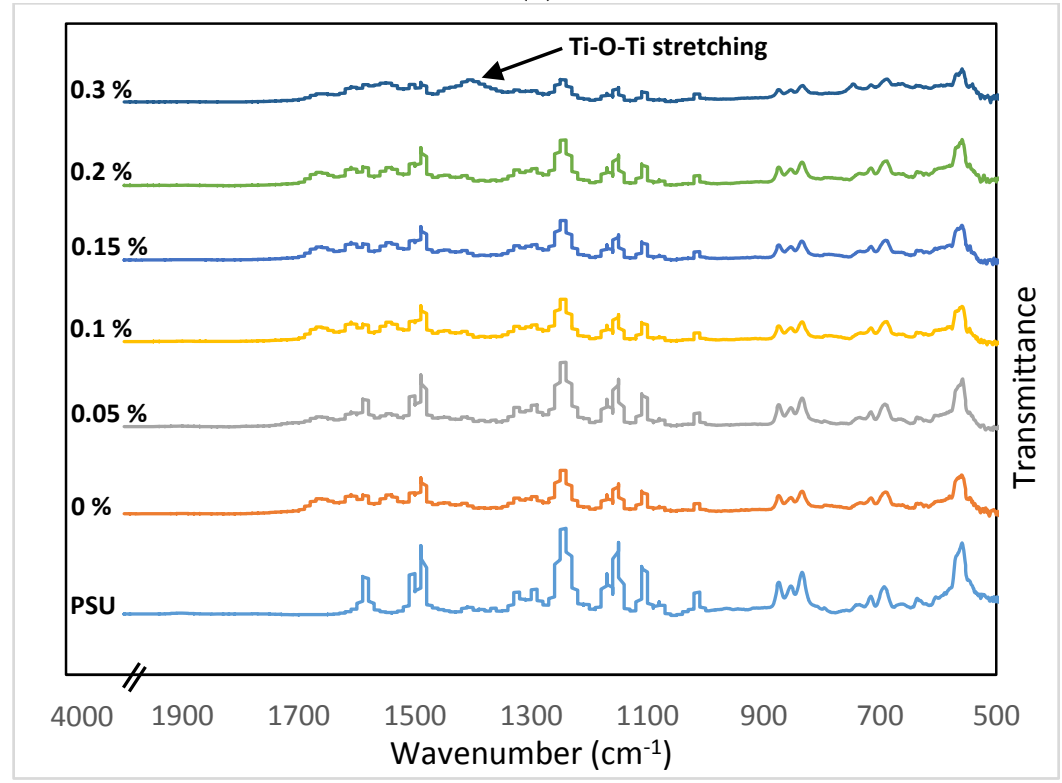

(b)

Figure 3. Attenuated total reflection Fourier transform infrared (ATR FT-IR) spectra for (a) UiO-66 and (b) MIL-125. 


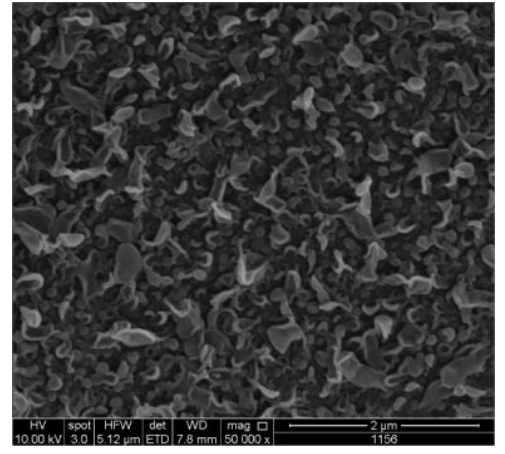

(a)

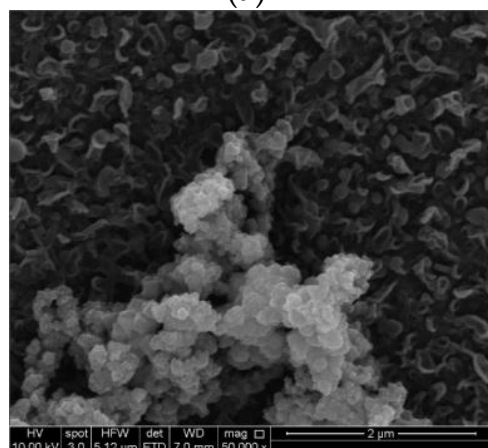

(d)

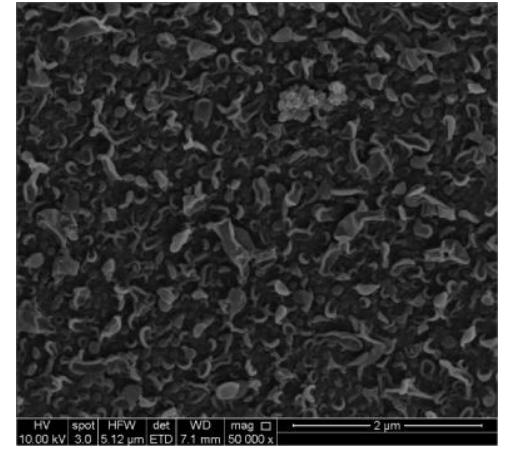

(b)

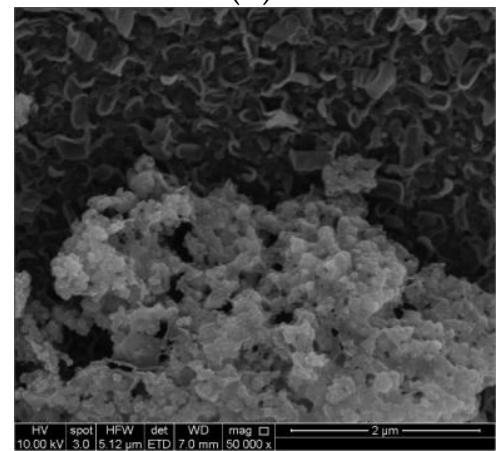

(e)

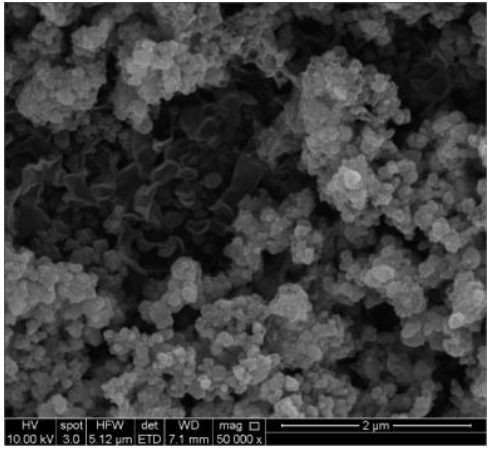

(c)

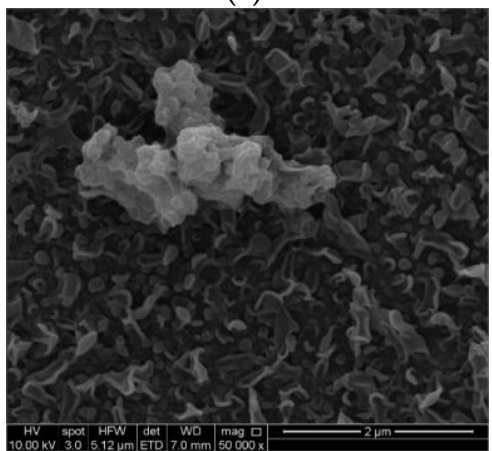

(f)

Figure 4. SEM images for membranes surface with UiO-66 NPs injection, (a) $0 \%$, (b) $0.05 \%$, (c) $0.1 \%$, (d) $0.15 \%$, (e) $0.2 \%$, and (f) $0.3 \%$.

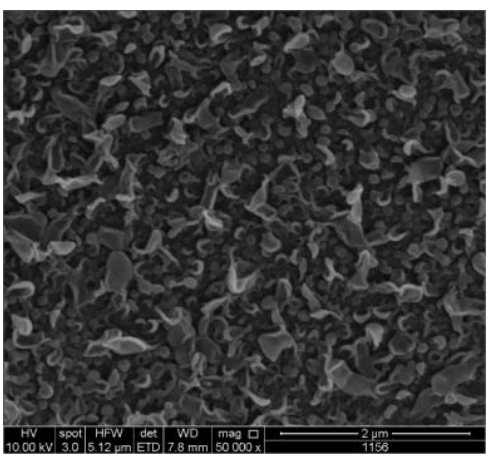

(a)

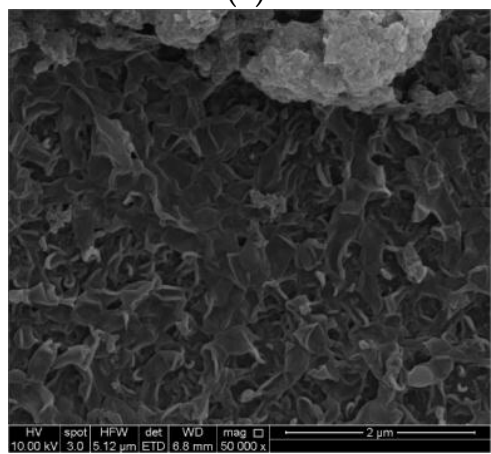

(d)

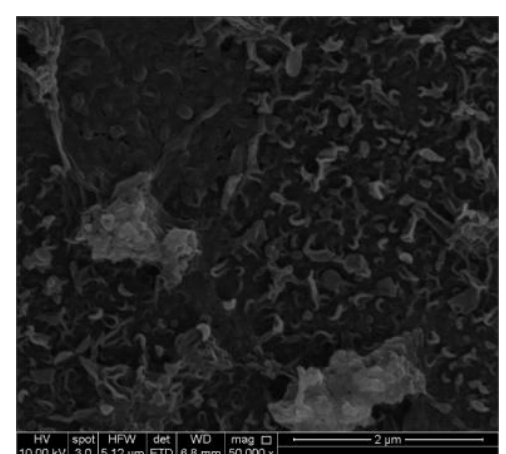

(b)

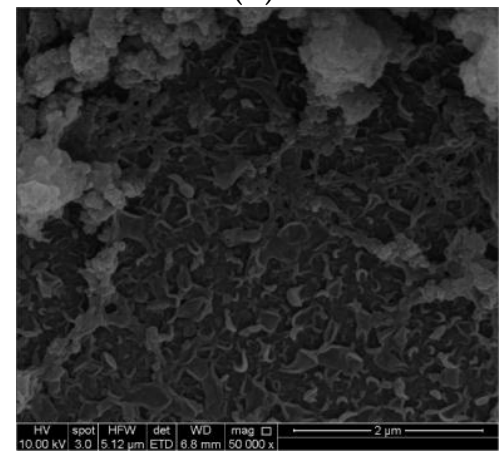

(e)

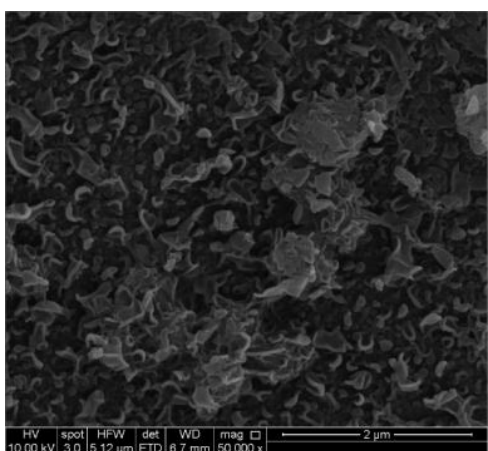

(c)

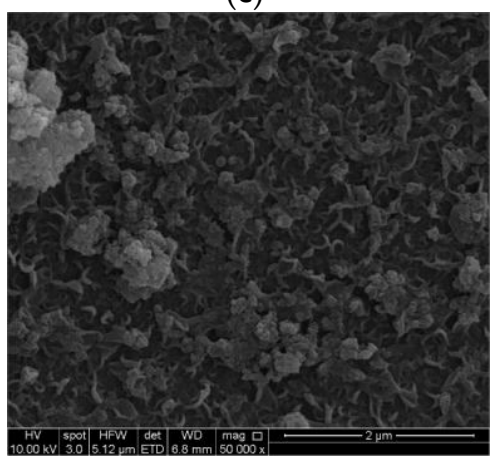

(f)

Figure 5. SEM images for membranes surface with MIL-125 NPs injection, (a) $0 \%$, (b) $0.05 \%$, (c) $0.1 \%$, (d) $0.15 \%$, (e) $0.2 \%$, and (f) $0.3 \%$. 
In Figure 5, the impact of embedding MIL-125 NPs on the morphology was presented. Unlike UiO-66 filling, MIL-125 appeared to have changed the leaf-shaped morphology, in addition to the aggregation. The leaves are connected to each other, making long leaves. This could be because of MIL-125's quasi-cubic tetragonal structure, or the smaller size of MIL-125 comparing with UiO-66 NPs, which might give better filling into the membrane.

Figure 6 shows the measured contact angles between DI water drop and the membrane's surface. By adding the MOFs NPs, the contact angle did not decrease significantly. The result is different from filling other nanomaterials such as hydrophilic silica [18] and oxidized graphene [78] where significant decreases of contact angle were observed. This may be attributed to the MOFs structure, which contains organic linkers surrounding the metal core. The organic part is slightly hydrophobic, leading to decreased particle hydrophilicity [38]. From the figure, the UiO-66 had more hydrophilic effect than MIL-125. This could be because MIL-125 has more linkers on the surface shielding the metal atom. The observation is also in consistence with the fact that MIL-125 had a higher surface area.

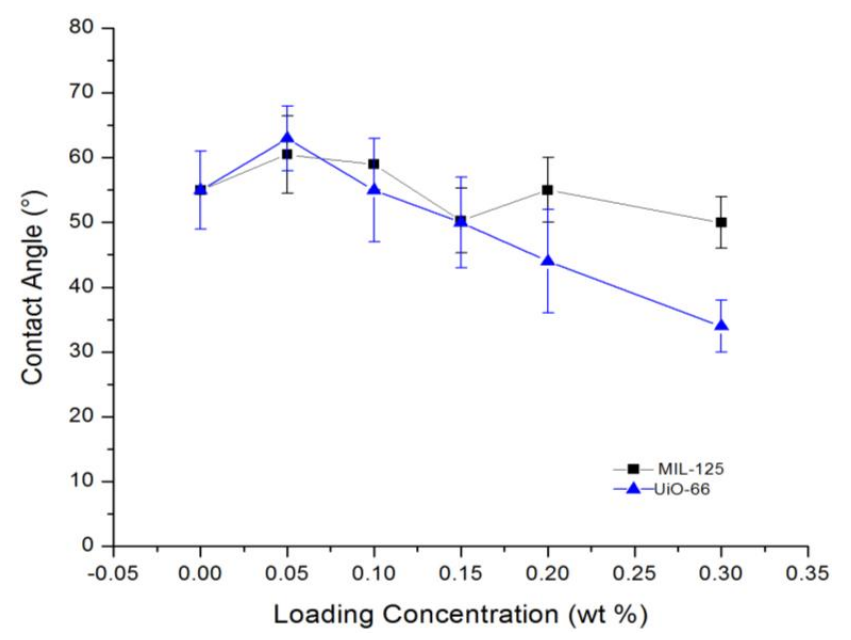

Figure 6. Pure water contact angle with the modified thin film nanocomposite (TFN) membranes surface.

TEM cross section images for the plain membrane and UiO-66 and MIL-125 nanocomposite membranes are illustrated in Figure $7 \mathrm{a}-\mathrm{c}$, respectively. Figure $7 \mathrm{~b}$ is the cross-sectional view of TFN membrane at an optimal UiO-66 NPs loading $(0.15 \%)$; while Figure $7 \mathrm{c}$ is at an optimal MIL-125 NPs loading $(0.3 \%)$. The TEM examination showed that the particles were filled into the membranes and appeared as black clusters; MIL-125 NPs were highly homogenized with the membrane and affected its texture. From the images, the membrane thickness is found to be $200-400 \mathrm{~nm}$.

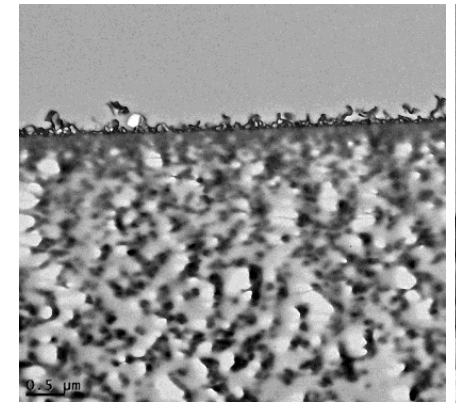

(a)

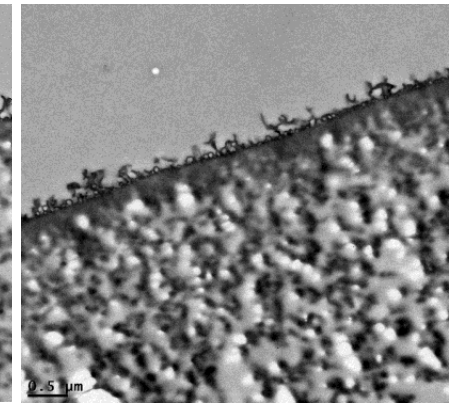

(b)

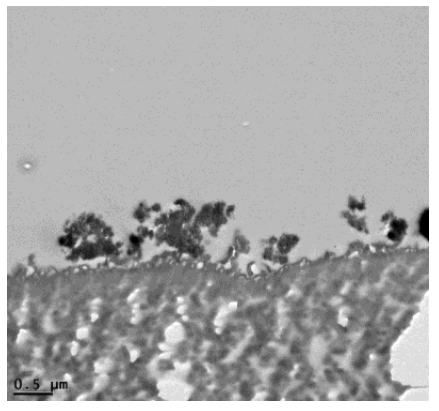

(c)

Figure 7. Transmission electron microscopy (TEM) images of (a) thin film composite (TFC) membrane, (b) TFN membrane of $0.15 \%$ UiO-66, and (c) TFN membrane of $0.3 \%$ MIL-125. 


\subsection{TFN Membranes Performance}

The salt rejection and water flux for UiO-66 and MIL-125 modified membranes were documented in Figure 8a,b. For UiO-66, the optimal addition was $0.15 \%$, where the permeate water flux and salt rejection increased from $62.5 \mathrm{~L} / \mathrm{m}^{2} \mathrm{~h}$ and $98.4 \%$ to $74.9 \mathrm{~L} / \mathrm{m}^{2} \mathrm{~h}$ and $98.8 \%$, respectively. From Figure $8 \mathrm{a}$, adding UiO-66 NPs increased $\mathrm{NaCl}$ rejection at low loadings, but a further increase of the NPs resulted in a decrease of salt rejection. The rejection increase at low loading could be attributed to UiO-66's pore size $(\sim 6.0 \AA)$ [59], which is larger than water molecule $(\sim 2.8 \AA)$ but smaller than the hydrated ions $\left(\mathrm{Na}^{+}=7.16\right.$ and $\mathrm{Cl}^{-}=6.64 \AA$ ) [79]. Increasing the NPs amount too much could decrease salt rejection, as the particles aggregation may generate cracks in TFN membranes structure. On the other hand, the flux increase by adding NPs reached its maximum at $0.15 \%$. This is likely due to the hydrophilic nature of UiO-66 $[59,80]$. At percentages higher than $0.15 \%$, the water flux decreased, again likely due to NPs aggregation [13]. Here, both salt rejection and water flux decreased because of particle aggregation. Aggregation may have created micro gaps between particle blocs that allowed the saline water to pass through. The particle aggregates could also block the water transfer through the membrane by the hydrophobic linkers overlapping, thus decreased water flux. Thereby, reduction in both salt rejection and water flux occurred.

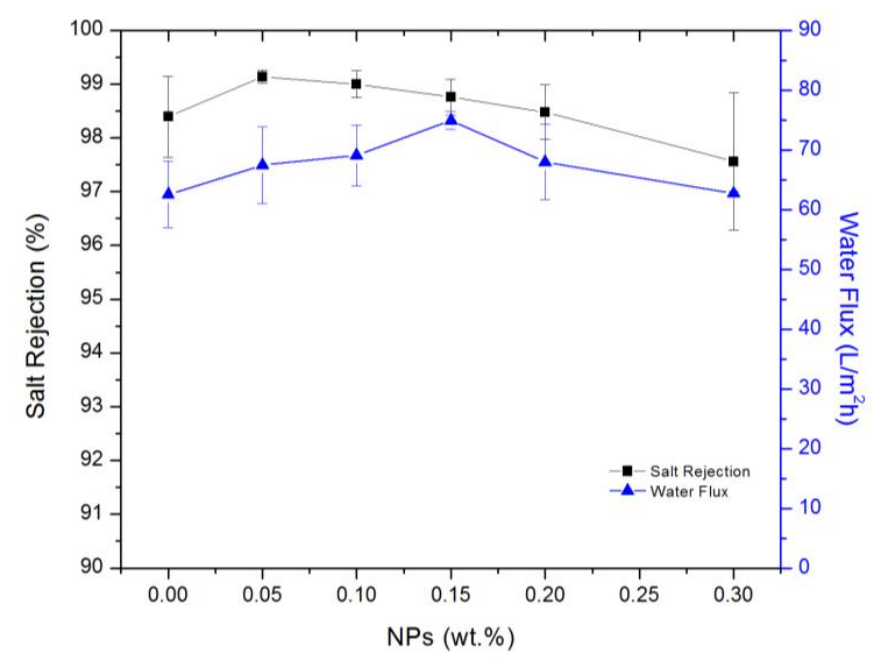

(a)

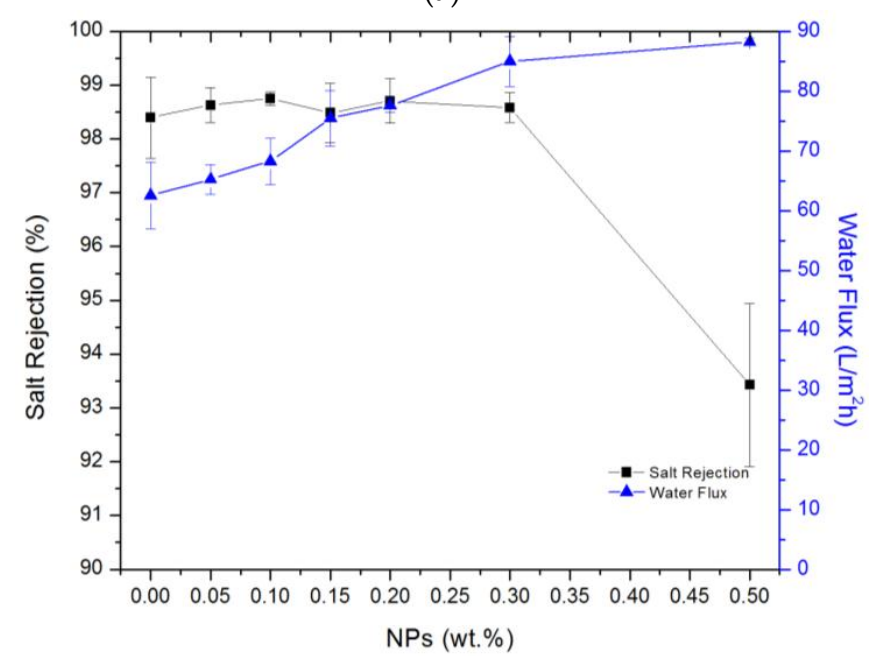

(b)

Figure 8. TFN membranes performance with injected (a) UiO-66 and (b) MIL-125 NPs. 
Figure $8 \mathrm{~b}$ shows the effect of adding MIL-125 NPs to TFN membrane. The water flux increased by increasing NPs loading, for example, with a solid loading of $0.3 \%$, the permeate water flux was increased from 62.5 to $85.0 \mathrm{~L} / \mathrm{m}^{2} \mathrm{~h}$, while the salt rejection maintained almost the same (98.4\% vs. $98.6 \%)$. At filling of $0.5 \%$ NPs, a drop in salt rejection happened. The effective pore diameter of MIL-125 is $12.55 \AA$ [60] which is larger than both the water molecule and hydrated ions of $\mathrm{Na}^{+}$and $\mathrm{Cl}^{-}$. However, the salt rejection remained the same even at a higher loading, the high negative charge of MIL-125 could play a role here as the formed electrical double layer could repel the negatively-charged ions. The reported water flux here at $0.3 \%, 85.0 \mathrm{~L} / \mathrm{m}^{2} \mathrm{~h}$, is considered one of the highest in comparison with the reported values in the literature [81]. The high flux could be due to the NPs hydrophilicity and their large surface area and pore size. Figure 9 shows the permeability of optimal membranes by adding $0.15 \mathrm{wt} \%$ of UiO- 66 or $0.3 \mathrm{wt} \%$ MIL-125 at different feed pressures.

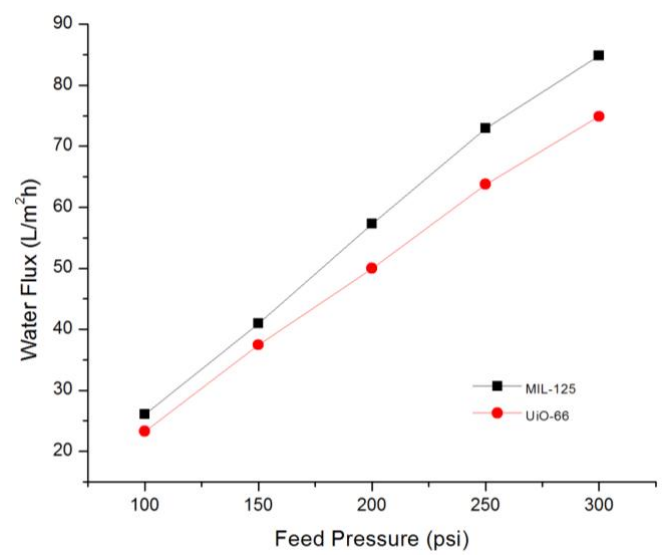

Figure 9. Membranes permeability at an optimal NPs filling.

\subsection{Why MOFs for TFN Membranes?}

MOFs are valuable materials due to their unique structure and wide applications in various areas [35]. It is anticipated that by the coming decade, mixed matrix membranes based on MOFs could grow, including those for large scale applications [38]. Among various nanocomposite membranes, MOFs-enabled membranes are advantageous because they can overcome the traditional filling problems of low affinity with the membrane, porosity blocking, and segregation $[82,83]$. The hybrid MOFs structure with organic and inorganic parts is generally compatible with polymeric layers in membrane [84]. This concept is illustrated in Figure 10, where MOFs particles can be more conveniently embedded into the TFN membrane with less gaps than those created by traditional inorganic fillers. Another advantage is the low cost of the polymeric membranes and the vast selection range of linkers toward controlling MOFs shape, morphology, and surface chemistry, making it potentially possible to design membrane for specific applications.

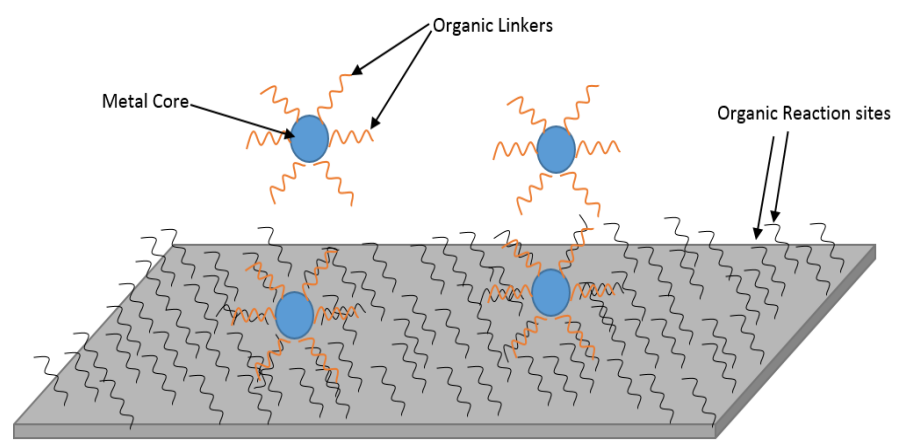

Figure 10. MOFs filling into polymeric substance diagram. 


\section{Conclusions}

Incorporation of UiO-66 and MIL-125 MOFs NPs in reverse osmosis membranes is reported in this study. The results showed that MOFs were embedded well inside the membranes and increased the water flux and salt rejection. Different techniques were used to exam the NPs and TFN membranes' physicochemical properties. The organic linker enhanced the compatibility of MOFs particles with the polyamide thin film. The results indicated that the water flux was increased from 62.5 to 74.9 or $85.0 \mathrm{~L} / \mathrm{m}^{2} \mathrm{~h}$ at a transmembrane pressure of $300 \mathrm{psi}$, by addition of $0.15 \%$ of UiO- 66 or $0.3 \%$ of MIL- 125 , respectively, while salt rejection was slightly increased. These high flux results indicate filling of MOFs NPs in TFN membrane might be advantageous because of the NPs containing an organic part that could link properly to polyamide, and inorganic part that could enhance the membrane performance.

Acknowledgments: We gratefully acknowledge the Higher Committee for Education Development in Iraq (HCED-Iraq) for supporting Mohammed Kadhom. The project was partial supported by the Missouri Water Resources Research Center. We would like to thank Qingsong Yu in the Department of Mechanical and Aerospace Engineering and Maria Fidalgo and Zhiqiang $\mathrm{Hu}$ in the Department of Civil and Environmental Engineering at the University of Missouri-Columbia for the access to contact angle video system, BET, and zeta potential device, respectively. We would like to acknowledge Martin Schauflinger from the Electron Microscopy Core at the University of Missouri-Columbia for his help in preparing and characterizing TEM samples.

Author Contributions: Mohammed Kadhom and Baolin Deng conceived and designed the experiments. Weiming $\mathrm{Hu}$ prepared the NPs. Mohammed Kadhom performed the experiments, analyzed the date, and wrote the first draft. All authors contributed to put the paper in its final form.

Conflicts of Interest: The authors declare no conflicts of interest.

\section{References}

1. Nobel, R.; Stern, S.A. Membrane Separations Technology Principles and Applications; Elsevier: Amsterdam, The Netherlands, 1995.

2. Service, R.F. Desalination Freshens Up. Science 2006, 313, 1088-1090. [CrossRef] [PubMed]

3. Sagle, A.; Freeman, B. Fundamentals of membranes for water treatment. Tex. Water Dev. 2004, 2, 137-153.

4. Cadotte, J. Interfacially Synthesized Reverse Osmosis Membrane. U.S. Patent 4,277,344, 7 July 1981.

5. Pabby, A.K.; Rizvi, S.S.; Sastre, A.M. Handbook of Membrane Separations: Chemical, Pharmaceutical, Food, and Biotechnological Applications; Taylor \& Francis Group: Boca Raton, FL, USA, 2015.

6. Dong, H.; Zhao, L.; Zhang, L.; Chen, H.; Gao, C.; Ho, W.S.W. High-flux reverse osmosis membranes incorporated with NaY zeolite nanoparticles for brackish water desalination. J. Membr. Sci. 2015, 476, 373-383. [CrossRef]

7. Lind, M.L.; Ghosh, A.K.; Jawor, A.; Huang, X.; Hou, W.; Yang, Y.; Hoek, E. Influence of zeolite crystal size on zeolite-polyamide thin film nanocomposite membranes. Langmuir 2009, 25, 10139-10145. [CrossRef] [PubMed]

8. Kong, C.L.; Shintani, T.; Tsuru, T. Pre-seeding assisted synthesis of a high performance polyamide-zeolite nanocomposite membrane for water purification. New J. Chem. 2010, 34, 2101-2104. [CrossRef]

9. Huang, H.; Qu, X.; Dong, H.; Zhang, L.; Chen, H. Role of NaA zeolites in the interfacial polymerization process towards a polyamide nanocomposite reverse osmosis membrane. RSC Adv. 2013, 3, 8203-8207. [CrossRef]

10. Huang, H.; Qu, X.; Ji, X.; Gao, X.; Zhang, L.; Chen, H.; Hou, L. Acid and multivalent ion resistance of thin film nanocomposite RO membranes loaded with silicalite-1 nanozeolites. J. Mater. Chem. A 2013, 1, 11343-11349. [CrossRef]

11. Dong, H.; Qu, X.Y.; Zhang, L.; Cheng, L.H.; Chen, H.L.; Gao, C.J. Preparation and characterization of surface-modified zeolite-polyamide thin film nanocomposite membranes for desalination. Desal. Water Treat. 2011, 34, 6-12. [CrossRef]

12. Li, L.; Dong, J.; Nenoff, T.M.; Lee, R. Desalination by reverse osmosis using MFI zeolite membranes. J. Membr. Sci. 2004, 243, 401-404. [CrossRef]

13. Yin, J.; Kim, E.; Yang, J.; Deng, B. Fabrication of a novel thin-film nanocomposite (TFN) membrane containing MCM-41 silica nanoparticles (NPs) for water purification. J. Membr. Sci. 2012, 423-424, 238-246. [CrossRef] 
14. Wu, H.; Tang, B.; Wu, P. Optimizing polyamide thin film composite membrane covalently bonded with modified mesoporous silica nanoparticles. J. Membr. Sci. 2013, 428, 341-348. [CrossRef]

15. Ma, X.; Lee, N.; Oh, H.; Hwang, J.; Kim, S. Preparation and characterization of silica/polyamide-imide nanocomposite thin films. Nanoscale Res. Lett. 2010, 5, 1846-1851. [CrossRef] [PubMed]

16. Tiraferri, A.; Kang, Y.; Giannelis, E.P.; Elimelech, M. Highly hydrophilic thin-film composite forward osmosis membranes functionalized with surface-tailored nanoparticles. Appl. Mater. Interfaces 2012, 4, 5044-5053. [CrossRef] [PubMed]

17. Jadav, G.L.; Singh, P.S. Synthesis of novel silica-polyamide nanocomposite membrane with enhanced properties. J. Membr. Sci. 2009, 328, 257-267. [CrossRef]

18. Kadhom, M.; Yin, J.; Deng, B. A thin film nanocomposite membrane with MCM-41 silica nanoparticles for brackish water purification. Membranes 2016, 6, 1-12. [CrossRef] [PubMed]

19. Emadzadeh, D.; Lau, W.J.; Matsuura, T.; Ismail, A.F.; Rahbari-Sisakht, M. Synthesis and characterization of thin film nanocomposite forward osmosis membrane with hydrophilic nanocomposite support to reduce internal concentration polarization. J. Membr. Sci. 2014, 449, 74-85. [CrossRef]

20. Yadaa, M.; Inouea, Y.; Akihitoa, G.; Nodab, I.; Torikaia, T.; Wataria, T.; Hotokebuchi, T. Apatite-forming ability of titanium compound nanotube thin films formed on a titanium metal plate in a simulated body fluid. Colloids Surf. B Biointerfaces 2010, 80, 116-124. [CrossRef] [PubMed]

21. Emadzadeha, D.; Laua, W.J.; Matsuura, T.; Hilal, N.; Ismail, A.F. The potential of thin film nanocomposite membrane in reducing organic fouling in forward osmosis process. Desalination 2014, 348, 82-88. [CrossRef]

22. Tettey, K.E.; Yee, M.Q.; Lee, D. Photocatalytic and conductive $\mathrm{MWCNT} / \mathrm{TiO}_{2}$ nanocomposite thin films. Appl. Mater. Interfaces 2010, 2, 2646-2652. [CrossRef] [PubMed]

23. Shen, J.; Yu, C.; Ruan, H.; Gao, C.; Bruggen, B.V. Preparation and characterization of thin-film nanocomposite membranes embedded with poly(methyl methacrylate) hydrophobic modified multiwalled carbon nanotubes by interfacial polymerization. J. Membr. Sci. 2013, 442, 18-26. [CrossRef]

24. Roy, S.; Ntim, S.A.; Mitra, S.; Sirkar, K.K. Facile fabrication of superior nanofiltration membranes from interfacially polymerized CNT-polymer composites. J. Membr. Sci. 2011, 375, 81-87. [CrossRef]

25. Ma, L.; Dong, X.; Chen, M.; Zhu, L.; Wang, C.; Yang, F.; Dong, Y. Fabrication and Water Treatment Application of Carbon Nanotubes (CNTs)-Based Composite Membranes: A Review. Membranes 2017, 7, 1-21. [CrossRef] [PubMed]

26. Ghosh, A.K.; Jeong, B.-H.; Huang, X.; Hoek, E.M.V. Impacts of reaction and curing conditions on polyamide composite reverse osmosis membrane properties. J. Membr. Sci. 2008, 311, 34-45. [CrossRef]

27. Ding, C.; Yin, J.; Deng, B. Effects of polysulfone (PSf) support layer on the performance of thin-film composite (TFC) membranes. J. Chem. Process Eng. 2014, 1, 1-8. [CrossRef]

28. Kuehne, M.A.; Song, R.Q.; Li, N.N.; Petersen, R.J. Flux enhancement in TFC RO membranes. Enivron. Prog. 2001, 20, 23-26. [CrossRef]

29. Zhao, L.; Ho, W.S.W. Novel reverse osmosis membranes incorporated with a hydrophilic additive for seawater desalination. J. Membr. Sci. 2014, 455, 44-54. [CrossRef]

30. Gu, H.; Rahardianto, A.; Gao, L.X.; Christof, P.D.; Cohen, Y. Ultrafiltration with self-generated RO concentrate pulse backwash in a novel integrated seawater desalination UF-RO system. J. Membr. Sci. 2016, 520, 111-119. [CrossRef]

31. Hai, Y.; Zhang, J.; Shi, C.; Zhou, A.; Bian, C.; Li, W. Thin film composite nanofiltration membrane prepared by the interfacial polymerization of 1,2,4,5-benzene tetracarbonyl chloride on the mixed amines cross-linked poly(ether imide) support. J. Membr. Sci. 2016, 520, 19-28. [CrossRef]

32. Shaffer, D.L.; Yip, N.Y.; Gilron, J.; Elimelech, M. Seawater desalination for agriculture by integrated forward and reverse osmosis: Improved product water quality for potentially less energy. J. Membr. Sci. 2012, 415-416, 1-8. [CrossRef]

33. Elimelech, M.; Phillip, W.A. The future of sea water desalination: Energy, technology, and the environment. Science 2011, 333, 712-717. [CrossRef] [PubMed]

34. Fritzmann, C.; Löwenberg, J.; Wintgens, T.; Melin, T. State-of-the-art of reverse osmosis desalination. Desalination 2007, 216, 1-76. [CrossRef]

35. Li, W.; Zhang, Y.; Li, Q.; Zhang, G. Metal-organic framework composite membranes: Synthesis and separation applications. Chem. Eng. Sci. 2015, 135, 232-257. [CrossRef]

36. James, S.L. Metal-organic frameworks. Chem. Soc. Rev. 2003, 32, 276-288. [CrossRef] [PubMed] 
37. Li, J.; Sculley, J.; Zhou, H.C. Metal-organic frameworks for separations. Chem. Rev. 2012, 112, 869-932. [CrossRef] [PubMed]

38. Zornoza, B.; Tellez, C.; Coronas, J.; Gascon, J.; Kapteijn, F. Metal organic framework based mixed matrix membranes: An increasingly important field of research with a large application potential. Microporous Mesoporous Mater. 2013, 166, 67-78. [CrossRef]

39. Gascon, J.; Aktay, U.; Hernandez-Alonso, M.D.; van Klink, G.P.; Kapteijn, F. Amino-based metal-organic frameworks as stable, highly active basic catalysts. J. Catal. 2009, 261, 75-87. [CrossRef]

40. An, J.; Rosi, N. Tuning MOF $\mathrm{CO}_{2}$ adsorption properties via cation exchange. J. Am. Chem. Soc. 2010, 132, 5578-5579. [CrossRef] [PubMed]

41. Lee, C.Y.; Farha, O.K.; Hong, B.J.; Sarjeant, A.A.; Nguyen, S.T.; Hupp, J.T. Light-Harvesting MetalOrganic Frameworks (MOFs): Efficient Strut-to-Strut Energy Transfer in Bodipy and Porphyrin-Based MOFs. J. Am. Chem. Soc. 2011, 133, 15858-15861. [CrossRef] [PubMed]

42. Allendorf, M.D.; Bauer, C.A.; Bhakta, R.K.; Houk, R.J.T. Luminescent metal-organic frameworks. Chem. Soc. Rev. 2009, 38, 1330-1352. [CrossRef] [PubMed]

43. Ma, L.; Abney, C.; Lin, W. Enantioselective catalysis with homochiral metal-organic frameworks. Chem. Soc. Rev. 2009, 38, 1248-1256. [CrossRef] [PubMed]

44. Rocca, J.D.; Liu, D.; Lin, W. Nanoscale Metal-Organic Frameworks for Biomedical Imaging and Drug Delivery. Acc. Chem. Res. 2011, 44, 957-968. [CrossRef] [PubMed]

45. Murray, L.J.; Dincă, M.; Long, J.R. Hydrogen storage in metal-organic frameworks. Chem. Soc. Rev. 2009, 38, 1294-1314. [CrossRef] [PubMed]

46. Hu, Y.H.; Zhang, L. Hydrogen Storage in Metal-Organic Frameworks. Adv. Mater. 2010, 22, E117-E130. [CrossRef] [PubMed]

47. Li, J.-R.; Kuppler, R.J.; Zhou, H.C. Selective gas adsorption and separation in metal-organic frameworks. Chem. Soc. Rev. 2009, 38, 1477-1504. [CrossRef] [PubMed]

48. An, J.; Geib, S.J.; Rosi, N.L. High and selective $\mathrm{CO}_{2}$ uptake in a cobalt adeninate metal-organic framework exhibiting pyrimidine- and amino-decorated pores. J. Am. Chem. Soc. 2010, 132, 38-39. [CrossRef] [PubMed]

49. Farha, O.K.; Eryazici, I.; Jeong, N.C.; Hauser, B.G.; Wilmer, C.E.; Sarjean, A.A.; Snurr, R.Q.; Nguyen, S.T.; Yazaydın, A.O.; Hupp, J.T. Metal-Organic Framework Materials with Ultrahigh Surface Areas: Is the Sky the Limit? J. Am. Chem. Soc. 2012, 134, 15016-15021. [CrossRef] [PubMed]

50. Liu, Y. Synthesis of continuous MOF-5 membranes on porous a-alumina substrates. Microporous Mesoporous Mater. 2009, 118, 296-301. [CrossRef]

51. Shen, J.; Liu, G.; Huang, K.; Li, Q.; Guan, K.; Li, Y.; Jin, W. UiO-66-polyether block amide mixed matrix membranes for $\mathrm{CO}_{2}$ separation. J. Membr. Sci. 2016, 513, 155-165. [CrossRef]

52. Wang, C.; Liu, X.; Chen, J.P.; Li, K. Superior removal of arsenic from water with zirconium metal-organic framework UiO-66. Sci. Rep. 2015, 5, 1-10. [CrossRef] [PubMed]

53. Liu, X.; Demir, N.K.; Wu, Z.; Li, K. Highly water-stable zirconium metal-organic framework UiO-66 membranes supported on alumina hollow fibers for desalination. J. Am. Chem. Soc. 2015, 137, 6999-7002. [CrossRef] [PubMed]

54. Lee, J.-Y.; Tang, C.Y.; Huo, F. Fabrication of porous matrix membrane (PMM) using metal-organic framework as green template for water treatment. Sci. Rep. 2014, 4, 3740. [CrossRef] [PubMed]

55. Hu, Z.; Chen, Y.; Jiang, J. Zeolitic imidazolate framework-8 as a reverse osmosis membrane for water desalination: Insight from molecular simulation. J. Chem. Phys. 2011, 134, 134705. [CrossRef] [PubMed]

56. Gupta, K.; Zhang, K.; Jiang, J. Water desalination through zeolitic imidazolate framework membranes: Significant role of functional groups. Langmuir 2015, 31, 13230-13237. [CrossRef] [PubMed]

57. Xu, Y.; Gao, X.; Wang, X.; Wang, Q.; Ji, Z.; Wang, X.; Wu, T.; Gao, C. Highly and stably water permeable thin film nanocomposite membranes doped with MIL-101 (Cr) nanoparticles for reverse osmosis application. Materials 2016, 9, 870. [CrossRef]

58. Ma, D.; Peh, S.B.; Han, G.; Chen, S.B. Thin-film nanocomposite (TFN) membranes incorporated with super-hydrophilic metal-organic framework (MOF) UiO-66: Toward enhancement of water flux and salt rejection. ACS Appl. Mater. Interfaces 2017, 9, 7523-7534. [CrossRef] [PubMed]

59. Cavka, J.H.; Jakobsen, S.; Olsbye, U.; Guillou, N.; Lamberti, C. A new zirconium inorganic building brick forming metal organic frameworks with exceptional stability. J. Am. Chem. Soc. 2008, 130, 13850-13851. [CrossRef] [PubMed] 
60. Dan-Hardi, M.; Serre, C.; Frot, T.; Rozes, L.; Maurin, G.; Sanchez, C.; Férey, G. A new photoactive crystalline highly porous titanium(IV) dicarboxylate. J. Am. Chem. Soc. 2009, 131, 10857-10859. [CrossRef] [PubMed]

61. Jasuja, H.; Jiao, Y.; Burtch, N.C.; Huang, Y.-G.; Walton, K.S. Synthesis of cobalt, nickel, copper, and zinc-Based, water-Stable, pillared metal-organic frameworks. Langmuir 2014, 30, 14300-14307. [CrossRef] [PubMed]

62. Devic, T.; Serre, C. High valence 3p and transition metal based MOFs. Chem. Soc. Rev. 2014, 43, 6097-6115. [CrossRef] [PubMed]

63. Jeremias, F.; Lozan, V.; Henninger, S.K.; Janiak, C. Programming MOFs for water sorption: Aminofunctionalized MIL-125 and UiO-66 for heat transformation and heat storage applications. Dalton Trans. 2013, 42, 15967-15973. [CrossRef] [PubMed]

64. Stassen, I.; Styles, M.; van Assche, T.; Campagnol, N.; Fransaer, J.; Denayer, J.; Tan, J.-C.; Falcaro, P.; de Vos, D.; Ameloot, R. Electrochemical film deposition of the zirconium metal-organic framework UiO-66 and application in a miniaturized sorbent trap. Chem. Mater. 2015, 27, 1801-1807. [CrossRef]

65. Kandiah, M.; Nilsen, M.H.; Usseglio, S.; Jakobsen, S.; Tilset, M.; Larabi, C.; Quadrelli, E.A.; Bonino, F.; Lillerud, K.P. Synthesis and stability of tagged UiO-66 Zr-MOFs. Chem. Mater. 2010, 22, 6632-6640. [CrossRef]

66. Seo, Y.S.; Khan, N.A.; Jhung, S.H. Adsorptive removal of methylchlorophenoxypropionic acid from water with a metal-organic framework. Chem. Eng. J. 2015, 270, 22-27. [CrossRef]

67. Wang, H.; Yuan, X.; Wu, Y.; Zeng, G.; Dong, H.; Chen, X.; Leng, L.; Wu, Z.; Peng, L. In situ synthesis of In2S3@MIL-125(Ti) core-shell microparticle for the removal of tetracycline from wastewater by integrated adsorption and visible-light-driven photocatalysis. Appl. Catal. B Environ. 2016, 186, 19-29. [CrossRef]

68. Wang, H.; Yuan, X.; Wu, Y.; Zeng, G.; Chen, X.; Leng, L.; Wu, Z.; Jiang, L.; Li, H. Facile synthesis of amino-functionalized titanium metal-organic frameworks and their superior visible-light photocatalytic activity for Cr(VI) reduction. J. Hazard. Mater. 2015, 286, 187-194. [CrossRef] [PubMed]

69. Deng, H.; Xu, Y.; Chen, Q.; Wei, X.; Zhu, B. High flux positively charged nanofiltration membranes prepared by UV-initiated graft polymerization of methacrylatoethyl trimethyl ammonium chloride (DMC) onto polysulfone membranes. J. Membr. Sci. 2011, 366, 363-372. [CrossRef]

70. Tarboush, B.A.; Rana, D.; Matsuuraa, T.; Arafat, H.; Narbaitz, R. Preparation of thin-film-composite polyamide membranes for desalination using novel hydrophilic surface modifying macromolecules. J. Membr. Sci. 2008, 325, 166-175. [CrossRef]

71. Lee, H.; Im, S.; Kim, J.; Kim, H.; Kim, J.; Min, B. Polyamide thin-film nanofiltration membranes containing $\mathrm{TiO}_{2}$ nanoparticles. Desalination 2008, 219, 48-56. [CrossRef]

72. Shawky, H.; Chae, S.; Lin, S.; Wiesner, M. Synthesis and characterization of a carbon nanotube/polymer nanocomposite membrane for water treatment. Desalination 2011, 272, 46-50. [CrossRef]

73. Simmons, C. Corrosion of heavy-metal fluoride glasses. In Corrosion of Glass, Ceramics and Ceramic Superconductors: Principles, Testing, Characterization and Applications; Noyes Publications: Park Ridge, NJ, USA, 1992.

74. Toullec, M.L.; Simmons, C.J.; Simmons, J.H. Infrared spectroscopic studies of the hydrolysis reaction during leaching of heavy-metal fluoride glasses. J. Am. Chem. Soc. 1988, 71, 219-224. [CrossRef]

75. Sarkar, D.; Mohapatra, D.; Ray, S.; Bhattacharyya, S.; Adak, S.; Mitra, N. Synthesis and characterization of sol-gel derived $\mathrm{ZrO}_{2}$ doped $\mathrm{Al}_{2} \mathrm{O}_{3}$ nanopowder. Ceram. Int. 2007, 33, 1275-1282. [CrossRef]

76. Liu, H.; Sun, X.; Yin, C.; Hu, C. Removal of phosphate by mesoporous $\mathrm{ZrO}_{2}$. J. Hazard. Mater. 2008, 151, 616-622. [CrossRef] [PubMed]

77. Vetrivel, V.; Rajendran, K.; Kalaiselvi, V. Synthesis and characterization of Pure Titanium dioxide nanoparticles by Sol- gel method. Int. J. ChemTech Res. 2015, 7, 1090-1097.

78. Perreault, F.; Tousley, M.E.; Elimelech, M. Thin-film composite polyamide membranes functionalized with biocidal graphene oxide nanosheets. Environ. Sci. Technol. Lett. 2014, 1, 71-76. [CrossRef]

79. Nightingale, E.R.J. Phenomenological theory of ion solvation. Effective radii of hydrated ions. J. Phys. Chem. 1959, 63, 1381-1387. [CrossRef]

80. Furukawa, H.; Gándara, F.; Zhang, Y.-B.; Jiang, J.; Queen, W.L.; Hudson, M.R.; Yaghi, O.M. Water adsorption in porous metal-organic frameworks and related materials. J. Am. Chem. Soc. 2014, 136, 4369-4381. [CrossRef] [PubMed]

81. Zhao, L.; Chang, P.C.-Y.; Ho, W. High-flux reverse osmosis membranes incorporated with hydrophilic additives for brackish water desalination. Desalination 2013, 308, 225-232. [CrossRef] 
82. Nik, O.G.; Chen, X.Y.; Kaliaguine, S. Amine-functionalized zeolite FAU/EMT-polyimide mixed matrix membranes for $\mathrm{CO}_{2} / \mathrm{CH}_{4}$ separation. J. Membr. Sci. 2011, 379, 468-478. [CrossRef]

83. Bae, T.-H.; Liu, J.; Lee, J.S.; Koros, W.J.; Jones, C.W.; Nair, S. Facile high-yield solvothermal deposition of inorganic nanostructures on zeolite crystals for mixed matrix membrane fabrication. J. Am. Chem. Soc. 2009, 131, 14662-14663. [CrossRef] [PubMed]

84. Centrone, A.; Yang, Y.; Speakman, S.; Bromberg, L.; Rutledge, G.C.; Hatton, T.A. Growth of metal-organic frameworks on polymer surfaces. J. Am. Chem. Soc. 2010, 132, 15687-15691. [CrossRef] [PubMed] 